\title{
Construção simbólica da região e invenção da identidade: sobre a narrativa didática de Sebastião Paraná
}

\author{
Symbolic construction and invention \\ of identity: on the teaching of Sebastião Paraná narrative
}

Maria Aparecida Leopoldino*

\begin{abstract}
Resumo
Este trabalho trata da narrativa didática de Sebastião Paraná de Sá Sottomaio (1864-1938) presente no manual o Brasil e o Paraná, escrito originalmente em 1903 para uso das escolas primárias. Sua ampla aceitação entre os colegas do Ginásio Paranaense e da Escola Normal e as inúmeras reimpressões que recebeu sugere como suas ideias estavam em consonância com os conhecimentos considerados socialmente necessários à época. $\mathrm{Na}$ análise observa-se que o livro escolar, adotado na Escola Normal, produziu um saber sobre a geografia e a história do estado e elaborou um conceito de região que pudesse, ao mesmo tempo, caracterizar as fronteiras territoriais e definir uma "identidade" ao Paraná. Na busca por figurar um discurso de construção identitária, o autor elegeu os elementos que se originam dos produtos cultivados no espaço paranaense (erva-mate), do caráter do "povo" paranaense (pinheiro), da atividade manufatureira que atrairia o imigrante laboroso (café). Conclui-se que o esforço do intelectual em buscar raízes para explicar a especificidade regional constituiu-se em tarefa cívica e compromisso social de diversos letrados brasileiros que viveram os anos finais do século XIX e as décadas iniciais do século XX.
\end{abstract}

Palavras-chave: História regional, Sebastião Paraná, História da disciplina, Identidade regional

\begin{abstract}
This work deals with the teaching of Sebastião Paraná de Sá Sottomaio (18641938) narrative present in the manual Brazil and Parana, originally written in 1903 for use of primary schools. Its wide acceptance among Ginásio Paranaense e da Escola Normal and the numerous reprints that received suggests how his ideas were in line with the knowledge considered socially necessary for the time. The analysis shows that the texbook, adopted in Escola Normal, produced
\end{abstract}

\footnotetext{
*Doutora em Educação pela PUC/SP. Professora Associada do Departamento de Teoria e Prática da Educação da Universidade Estadual de Maringá. E-mail: leopoldino.mariaaparecida@yahoo.com.br
} 
a knowledge about the geography and history of the state and drew up a concept of region that could, at the same time, characterize the territorial borders and set an "identity" to the Paraná. In the serarch for na identity construct speech appear, the author hás chosen the elements that originate from products grown in space paranaense (yerba-mate), the character of the "people" paranaense (pine), manufacturing activity that would attractthe immigrant worker (coffee). Concludes that the intellectual effort for roots to explain region specificity consisted in civic and socially engagement task various literati Brazilians Who lived the final years of the 19th century and the early decades of the 20th century.

Keywords: Regional history, Sebastião Paraná, History of discipline, Regional identity.

"Entre os astros do Cruzeiro

És o mais belo a fulgir!

Paraná! Serás luzeiro! Avante! Para o porvir!"

A escrita da história do Brasil do século XIX trouxe para à discussão a necessidade de se conhecer a nação elementos da natureza que compunha o território nacional. Debate inconcluso, inventar a nação brasileira nos anos iniciais do século XX significava, para a elite no poder, apropriar-se de seu território, sua natureza e, então, escrever sua história. Nos anos iniciais da República, a preocupação com o território tornou-se uma permanência criando um discurso sobre sua formação e função econômica no desenvolvimento nacional, favorável à criação da questão da identidade brasileira e de sua "civilização". Foi um momento em que a cartografia e o cartografamento nacional tornaram-se prioridades e os investimentos governamentais incluíram além das viagens de expedições científicas para o interior a incorporação de conceitos como de sertão na produção de conhecimentos sobre a geografia e a história do país.

Nesse cenário, o esforço dos intelectuais em buscar raízes para explicar a especificidade regional constituiu-se em tarefa cívica e compromisso social de diversos letrados brasileiros que viveram os anos finais do século XIX e as décadas iniciais do século XX. Esse esforço era o metier de letrados provincianos que, atuando no cenário político-cultural nos diferentes espaços 
de sociabilidades, descreviam a paisagem local e desenhavam recortes geográficos com o fim de elaborarem conhecimentos sobre os espaços regionais.

Sebastião Paraná de Sá Sottomaio (1864-1938) é exemplar nesse sentido. Envolvido com as principais instituições culturais da época, em especial do Instituto Histórico e Geográfico Brasileiro (IHGB), Institutos internacionais ${ }^{1}$ e regionais, engajou-se no projeto de construir uma identidade regional. Nascido em Curitiba, intelectual de aspirações republicanas, intensificou os discursos sobre a região como forma de definir o território nacional e criar as tradições de uma região que deveria seguir na "vanguarda modernista".

Inicialmente catedrático de Geografia e Chorographia do Brasil, Sebastião Paraná ocupou também a cátedra de História Universal do Gymnasio Paranaense e da Escola Normal. Envolvido com as atividades dessa instituição e, em meio aos debates sobre a o papel da geografia para explicar a nacionalidade brasileira, ele contribuiu significativamente para difundir os alicerces da escrita de uma história escolar na qual a natureza constituiu-se como objeto principal de sua narrativa. No exercício do magistério, escreveu vários livros que pudessem expressar seus anseios patrióticos: Espaço Geográfico do Paraná (1889); Chorografia do Paraná (1899); O Brasil e o Paraná para escolas primárias (1903); Os Estados da República (1911); Paizes da América (1922); Galeria Paranaense (1922); Paizes da Europa (1926); Efemérides da Revolução de Outubro de 1930 no Estado do Paraná (1931).

Pertencente ao diminuto mundo letrado, Sebastião Paraná, filho e neto de militar ${ }^{2}$, atuou na produção de ideais que reforçavam a grandiosidade da pátria e a situação do Paraná em direção à civilização da nação num momento em que o debate sobre a educação escolar tornava-se o centro de preocupação da reforma social dos republicanos.

Este trabalho trata de um de seus escritos, o manual o Brasil e o Paraná, escrito originalmente em 1903 para uso das escolas primárias. Sua ampla aceitação entre os colegas do Ginásio e da Escola Normal e as inúmeras reimpressões que recebeu - $22^{\mathrm{a}}$ edição em 1941 - sugere o quanto suas ideias estavam em sintonia com os conhecimentos considerados socialmente necessários à época. A instituição paranaense tornou-se o lugar social no qual o autor

\footnotetext{
${ }^{1}$ Instituto Geográfico Argentino; do Instituto Histórico e Geográfico Brasileiro; do Instituto Histórico e Geográfico Parahybano; do Instituto Arqueológico e Geográfico Alagoano; do Instituto Histórico e Geográfico de Sergipe; do Instituto Histórico e Geográfico de São Paulo; do Instituto Histórico e Geográfico Catarinense; e outras instituições como: da Sociedade Geográfica de Lisboa; da Sociedade de Geografia do Rio de Janeiro; sócio efetivo do Centro de Letras do Paraná e da Academia de Letras do Paraná.

${ }^{2}$ Filho do Capitão Inácio de Sá Sottomaior e neto do Coronel de milícias do mesmo nome.
} 
tomou consciência política da ruptura cultural com o passado imperial e dos problemas a serem enfrentados por seu grupo social no tempo presente.

Ao problematizar os nexos relacionais existentes entre natureza, território e nação na construção narrativa de Sebastião Paraná, se objetiva enfatizar o papel instituinte dos conhecimentos produzidos por professores-autores ${ }^{3}$ que atuaram no ensino secundário e na Escola Normal da principal instituição de ensino da história da educação no Paraná nos anos iniciais do século XX. Conhecimentos que contribuíram para a produção de textos didáticos de diferentes campos disciplinares que vão, no decorrer daquele século, definindo o papel do ensino da História e da Geografia nos cursos de formação de professores.

A escolha do livro didático como fonte deste estudo possibilita visualizar tais dimensões e, ao mesmo tempo, sugere alguns pressupostos. Tal opção implica em reconhecer o texto didático envolvido em uma historicidade, portanto, num movimento complexo das relações internas e externas ao espaço escolar, de forma que é observada a estreita relação entre a elaboração dos programas de ensino, a construção dos livros didáticos e a posição social de seus autores. Nesse sentido, os livros didáticos, quando interrogados, permitem abordar as tramas relacionais de uma época, uma vez que se ligam à maneira de determinado grupo social significar o difuso passado à que se referem por meio de sua narrativa e organização textual com o objetivo de servir a um ou mais campo(s) disciplinar(es).

Este texto preocupa-se em compreender como a construção da história regional tornou-se objeto de políticas públicas para a educação nos anos iniciais do século XX durante a afirmação da república brasileira. Afirma-se, portanto, o caráter criativo dos sujeitos ao produzirem fundamentos políticos e pedagógicos para a disciplina escolar bem como os instrumentos e meios de divulgação e circulação institucional desses conhecimentos.

Para tanto, o escrito foi dividido em três partes: na primeira analisa como a questão da região e da identidade regional aparece como problema para a formação da representação de nação brasileira; na segunda, estuda a descrição dos elementos naturais do estado do Paraná como fundamento da busca da identidade regional; na última, apresenta uma síntese de como a educação escolar, por meio da narrativa histórica e geográfica, constrói os

\footnotetext{
${ }^{3} \mathrm{O}$ conceito de professor-autor refere-se aos indivíduos que, nesse período, participavam da vida pública pela projeção intelectual e política. Sujeitos que publicavam seus escritos na imprensa, nos livros e artigos, além de exercerem o magistério em instituições de ensino secundário e superior.
} 
conteúdos da história e da geografia regional e, simbolicamente, a identidade paranaense por meio dos elementos naturais descritos pelo autor.

\section{A natureza como questão identitária}

Em 1903, na sede do Gymnasio Paranaense, a comissão designada para avaliar o livro de Sebastião Paraná - Emiliano Perneta, Chichorro Junior, Dario Vellozo - publica o seguinte parecer:

Cidadão Dr. Victor Ferreira do Amaral, D.D. Director da Instrucção Publica do Paraná. A comissão abaixo assignada, por vós nomeada para dar parecer sobre o livro do Dr. Sebastião Paraná - O Brasil e o Paraná - escripto PARA USO DAS ESCOLAS PRIMARIAS, - tendo estudado convenientemente o trabalho do illustre collega, entende que o referido livro preenche com brilho os fins a que se propoz o autor, devendo ser adoptado nas escolas publicas do Estado.

Escripto com amor pela terra natal - o Brasil e o Paraná - põe em bello relevo, não só a Patria Brasileira, senão tambem, e principalmente, este radioso Estado, digno de ser conhecido, para que realize desde logo o bello destino para que o fadou a Natureza.

É conhecendo o berço que o homem aprende a amal-o. o Brasil e o Paraná ensina-o sufficientemente, offerecendo rutilante exemplo, communicativo, de veneração e civismo. Coritiba, 1 de Outubro de 1903. ${ }^{4}$

Ao se eleger o manual de Sebastião Paraná como capaz de cumprir a missão cívica de apresentar o estado do Paraná, os lentes do Ginásio contribuíram para a criação de uma memória social, uma tradição discursiva da geografia e da história do Paraná que deveria ser ensinada desde a escola primária (os anos iniciais do ensino fundamental).

Sebastião Paraná se encontrava, nos anos iniciais da república paranaense, em meio aos debates que envolviam a escrita da história e o papel da geografia para explicar a nacionalidade brasileira e, mais especificamente, nela situar a identidade regional. Pertencente ao diminuto mundo letrado onde atuavam como professores e autores na principal instituição de ensino do Paraná - Ginásio Paranaense e Escola Normal - o intelectual produziu conhecimentos geográficos tendo seus pares como interlocutores e a sua atuação como professor de Geografia e História no ensino escolar como espaço de atuação política. Nesse aspecto, o Ginásio Paranaense, que mantinha também a Escola Normal, participou da "causa educacional" mediada pela intelectualidade que desejava ampliar a instrução escolar no estado. Por isso, a instituição

${ }^{4}$ PARANÁ, Sebastião. O Brasil e o Paraná: para uso das escolas primárias. $19^{a}$ edição melhorada. Curitiba: Empreza Graphica Paranaense, 1929, p.3. 
cumpriu sua função de preparar as elites locais para os preparatórios aos cursos superiores ou para ingressar no Colégio Pedro II, bem como ocupar cargos políticos, e, ao mesmo tempo, na tarefa de formar professores para as escolas primárias do estado. ${ }^{5}$

Por intermédio da Congregação, os catedráticos tomavam decisões sobre a organização pedagógica e desenvolvimento das ações administrativas da instituição. Era o conselho deliberativo sobre a adoção de livros didáticos e sobre a emissão de pareceres sobre obras didáticas encaminhadas para avaliação. Do conjunto de membros do Ginásio Paranaense sobressaia um núcleo de intelectuais constituído de indivíduos, em geral de origens e laços sociais privilegiados, que participavam ativamente da produção de uma representação de região, seja na fixação do objeto da Geografia, seja na aprovação, produção e circulação de manuais e compêndios que buscavam definir um campo de saber para uma disciplina escolar em construção.

Sebastião Paraná sendo professor catedrático de Geografia e História da Escola Normal lançou seu livro no cinqüentenário aniversário de autonomia provincial, em 1903. Especialmente voltado para o uso nas escolas primárias, o manual estava dirigido ao uso dos professores em formação. Para fazer surgir o território nacional, o autor se esforça em descrever o espaço natural e social por meio de temas diversificados: geográfico, histórico, etnográfico, dos quais dependia o mapeamento do território, com vistas à definição de fronteiras e de sua identidade nacional.

Limites e linhas divisórias, superfície, potamographia, colpographia, nesographia, riqueza natural, industria agricula, industria pastoril, industria fabril, industria extrativa, governo do Estado, divisão administrativa, representação federal, força publica, instrução popular, população, vias de comunicação, vias férreas, cidades, vilas, são os temas que compõem o conjunto textual do manual de Sebastião Paraná. Um conjunto de elementos e informações que são indicativas de que na sua construção narrativa a ocupação do interior - os sertões - deveria se realizar por meio do domínio e exploração cientifica, registrando e cartografando suas características naturais. A lógica exploratória seria: primeiro conhecer para descobrir o que depois se deveria explorar de suas potencialidades em prol do progresso nacional.

${ }^{5}$ TOLEDO, Maria A. Leopoldino Tursi. A disciplina de História no Paraná: os compêndios de História e a história ensinada (1876-1905). Tese de doutorado. Programa Educação: História, Política, Sociedade. Pontifícia Universidade Católica de São Paulo. 2005. 
Segundo o trabalho de Chistiane Marques Szesz ${ }^{6}$, no final do século XIX, o termo região aparece associado ao debate sobre a ideia de natureza, como sinônimo de "região natural". o debate incorpora o conceito tendo por base um conjunto relativamente homogêneo de elementos da natureza, como relevo, clima, vegetação e outros congêneres que configurariam uma parcela do território nacional. É nesse sentido que Sebastião Paraná conduz sua definição.

Baias, portos, ilhas; são mencionadas para qualificar o espaço e oferecer um quadro geral descritivo do território paranaense conhecido e a conhecer. o papel que este intelectual concebeu para os rios nesse enredo aponta não apenas à determinação geográfica de se conhecer o Paraná, mas também para o entendimento de que a sua história vinculava-se a essas determinações. Vencer a natureza bruta, adentrar as matas "virgens", os rios encachoeirados, apropriar-se dos espaços "vazios" tomando posse do território e produzir riquezas, eis a narrativa elaborada sobre o espaço.

Tendo como ponto de partida agregar a demarcação regional ao território da nação, o autor organiza seu manual de forma a permitir a compreensão de que as fronteiras e seus limites divisórios estavam demarcados pelos seus aspectos naturais. Na primeira parte do livro informa o que era a geografia do território nacional. Sua síntese é a de que “[...] Graças ás differenças do relevo e das latitudes, o Brasil tem quasi todos os climas, desde o quente do litoral e dos sertões, atravessados pelos grandes rios, até o temperado e frio dos planaltos" ?

Tais descrições geográficas constituíam o "domínio" do território, uma condição fundamental para a conquista de conhecimentos sobre sua natureza, riquezas e exploração e, ao mesmo tempo, condição para exaltar a pujança da natureza exibida e a ser ensinada com orgulho. Segue sua narrativa: “[...] Tão vasto é o Brasil que, naturalmente, se divide em grandes regiões distinctas, não obstante a unidade geographica do todo". ${ }^{8}$

A grandeza do território nacional deveria ser conhecida e exaltada pelos paranaenses, mas também pelas autoridades locais, a quem caberia utilizar o conhecimento produzido para o seu desenvolvimento industrial. Projeto que, por sua vez, demandava criação de vias de comunicação, pelo

\footnotetext{
${ }^{6}$ SZESZ, Chistiane Marques. A invenção do Paraná: O discurso regional e a definição das fronteiras cartográficas (1889-1920). Dissertação de Mestrado. Programa de Pós-Gradução em História do Brasil. Universidade Federal do Paraná. Curitiba, 1997.
}

${ }^{7}$ PARANÁ, op cit., p. 39

${ }^{8}$ PARANÁ, op cit., p. 39 
mar e por terra. Ideia que remete à intenção do autor de marcar a "extensão" e "integração" do regional ao nacional. Após mencionar as "bahias" de Paranaguá e de Guaratuba, por exemplo, atém-se na importância dos portos para o litoral do país com vistas ao desenvolvimento do comércio nacional.

A primeira [Paranaguá] é vasta e contém os portos seguintes: D.Pedro II, Antonina e Guarakessaba. É uma das mais vastas da costa brasileira. Infelizmente seu principal porto necessita de importantes melhoramentos para poder bem satisfazer o commercio de exportação e importação. ${ }^{9}$

Os rios aparecem, na abordagem de Sebastião Paraná, como vias naturais fixas que levavam aos limites territoriais e permitiam o desenvolvimento comercial para além de suas fronteiras. As referências aos roteiros estão sempre ligadas às suas condições para o possível trânsito comercial dos locais para outras regiões do país.

A barra de Guatauba acha-se balisada, podendo entrar nella navios sem que haja
receio dos perigos a que estavam sujeitos antes de se effectuar esse importante
melhoramento. É assignalada por um pharol, assim como a de Paranaguá,
indicada pelo pharol do morro das Conchas, na extremidade oriental da ilha
do Mel. ${ }^{10}$

Tornar as águas navegáveis, ampliar os contatos com outras regiões fazia parte das melhorias que o Paraná deveria passar para compor o cenário nacional de grandiosidade em seu caminho para o progresso e a civilização. Um tema que já era preocupação de outros atores sociais, a exemplo do secretário de obras públicas e colonização, João Baptista da Costa Carvalho, em 1895:

[...] informar a navegabilidade dos rios e seus afluentes, a natureza de seus territórios explorados, os produtos animal, vegetal e mineral. Estudar por onde se possa construir estradas, com maior economia afim de abrir a indústria e ao comércio e a civilização o imenso sertão uma das maiores riquezas do Paraná. ${ }^{11}$

Na elaboração de um discurso sobre o espaço regional, Sebastião produziu um conceito de região que pudesse, ao mesmo tempo, caracterizar as fronteiras territoriais e definir uma "identidade" ao Paraná. Utilizando-se dos escritos de viajantes ou excursionistas, definiu o espaço por aquilo que o diferenciava de outras regiões, quanto aos seus aspectos naturais. Além das questões de fronteiras vividas desde o século XIX com a Argentina e com

\footnotetext{
${ }^{9}$ PARANÁ, op cit., p.104, grifo meu.

${ }^{10}$ PARANÁ, op cit., p.104

${ }^{11}$ CARVALHO, João Baptista da Costa. Relatório. Apresentado ao Ex. Sr. Francisco Xavier da Silva em 25/10/1895. Curitiba: Impressora Paranaense, 1895, p.47
} 
o estado de Santa Catarina ${ }^{12}$, a narrativa sobre os elementos naturais que compunham a região, que então formava o Paraná, elabora o discurso da simbologia do estado como marca de sua identidade. ${ }^{13}$

A ênfase em conhecer, se apossar e explorar as riquezas naturais, por sua vez, secundariza a preocupação com a presença dos nativos presentes nesses espaços. No item "Nesographia" encontra-se a seguinte menção:

Nesses sambaquis [colinas, formadas de grande quantidade de cascas de crustáceos e molluscos], tambem vulgarmente chamados ostreiras, teem se encontrado ossos humanos, cinzas, carvão vegetal, fragmentos de louça de barro, espinhas de peixes, machados de pedra e outros utensílios de que se utilizavam os primeiros habitantes daquelles logares. ${ }^{14}$

Somente poucos comentários como esse aparecem para fazer referência à presença de grupos indígenas no território, vestígios que são, na narrativa, apagadas do processo de exploração e colonização do sertão. Os lugares são retratados como se estivessem vazios, conduzindo a interpretação de que a história desses espaços, com sua utilização e sua transformação humana, principia com a chegada do colono. Uma história que só começa, realmente, com a transformação do espaço pelo trabalho do "agente civilizador", como se vê nesse excerto em que o autor destaca:

O Paraná, Estado novo, de terras fertilíssimas e clima delicioso; Estado onde não existem preconceitos de raças e de seitas; Estado que dá generoso acolhimento aos extrangeiros, de cujo concurso precisa para a sua prosperidade material, possui grandes e admiráveis riquezas naturaes. É uma enorme officina aberta ao trabalho, a todas as especulações industriaes. ${ }^{15}$

Nessa representação, a configuração de uma malha social ocorreria na medida em que a acessibilidade de imigrantes e migrantes acontecesse e fosse significativa no traçado promissor do território a ser conhecido e divulgado. O núcleo da intenção de Sebastião com estes temas para explicar o Paraná caracteriza-se pela preocupação que tinha com a ocupação do território, seu desenvolvimento comercial e de relações de trabalho que poderia ali se firmar. Pressupõe-se uma forma de divulgar o território paranaense como capaz de

\footnotetext{
${ }^{12} \mathrm{Em}$ 1881, a Argentina definia sua interpretação da fronteira. $\mathrm{O}$ rio que os Argentinos denominaram Peperi-Guaçu, afluente do Uruguai, era conhecido como Chapecó pelos brasileiros. Já o rio Chopin, dos brasileiros, era o Santo Antônio, para os Argentinos. ( SZESZ, 1997).

${ }^{13}$ BAHLS, Aparecida V.S. A busca de valores identitários: a memória histórica paranaense. Tese de Doutorado. Programa de História. UFPR, 2007

${ }^{14}$ PARANÁ, op cit., p. 105

${ }^{15}$ PARANÁ, op cit., p. 106, grifo meu.
} 
desenvolver-se, uma vez que contava com a "fertilidade das terras", com o "clima favorável", com uma cultura não preconceituosa. Por meio do trabalho livre seria possível, direcionando os esforços e os meios para a exploração de seus recursos naturais, torná-lo grandioso para a pátria.

A espera pelos capitais para explorar as riquezas naturais é um eixo do discurso muito presente no manual. Esperava-se que os poderes públicos fossem as forças propulsoras desse desenvolvimento fazendo a propaganda da região e incentivando a imigração. Os esforços para conhecer a região, esquadrinhá-la, cartografá-la, seriam recompensados pelas riquezas que poderiam produzir por meio de seu cultivo. Seus atributos naturais eram, pois, uma questão nacional.

$\mathrm{Na}$ construção de um discurso que define a identidade regional, os elementos simbólicos da região se definiram, na narrativa de Sebastião Paraná, entre os produtos vegetais que eram produzidos nas terras paranaenses. Eles formaram a força simbólica ${ }^{16}$, o marco de origem $^{17}$, e o acordo político que definiu fronteiras e demarcou o território na representação de região. O esforço de convencimento é visível na imposição dessa visão ao conjunto social, de modo que esses elementos representativos da agricultura constituíssem nos símbolos da riqueza paranaense, sua legitimidade, grandeza e identidade. A educação escolar tornou-se num instrumento de convencimento dessas representações.

\section{A natureza como símbolo da identidade regional}

Na segunda parte do manual, Sebastião Paraná tratou especificamente da geografia do estado. A narrativa das dimensões físicas do espaço paranaense construiu o conceito de região e sua abordagem está voltada para o discurso do desenvolvimento da indústria e do comércio no estado. Nesse trajeto, destaca-se a presença de madeiras como originárias do território regional:

O reino vegetal é riquíssimo de madeiras excellentes para construcção civil e naval e para fabricação de objectos de marcenaria. Entre as madeiras mais estimadas que o Estado possue em grande cópia, destacam-se a imbuia, o angico,

\footnotetext{
${ }^{16}$ Este conceito se relaciona com o que Bourdieu denominou de "poder simbólico", que é "o poder de constituir o dado pela enunciação, de fazer ver e fazer crer, de confirmar ou de transformar a visão do mundo e, deste modo, a ação sobre o mundo." Ver: BOURDIEU, Pierre. Sobre o poder simbólico. In: O poder simbólico. Lisboa, Difel, 1989, p. 7-16

${ }^{17} \mathrm{O}$ conceito se aproxima a ideia de "Mito de Origem". Marilena Chauí (2000) trata deste conceito e esclarece que o mito neste caso não é só no sentido etimológico, de narração de acontecimentos lendários, "mas também no sentido antropológico, de solução imaginária para tensões; fundador por trazer um vínculo com um passado de origem, do qual não há nunca desvinculação". No caso deste trabalho, utiliza-se "marco" para reafirmar a importância historiográfica da questão. Ver: CHAUí, Marilena. Brasil: Mito fundador e sociedade autoritária. São Paulo: Fundação Perseu Abramo, 2000.
} 
o taruman, o jacarandá, o Angelim, o carvalho, a cajarãna, a cabreuva, o ipê, o jequitibá, o guaraperê, o balsamo, o jatahy, o cedro, o pinheiro, uma das mais abundantes. $^{18}$

A ênfase nos produtos vegetais que eram produzidos no território paranaense construiu um forte argumento de identidade, apoiado nas representações geográficas e na narrativa elaborada sobre suas características. Ao tratar da "indústria extrativa", Sebastião afirma:

É importante e consiste principalmente na extracção de pinho e de hervamatte, o mais valoroso producto da industriaextractiva paranaense. Região nenhuma da America foi melhor aquinhoada de hervaes do que o Paraná. Na zona de Serra-Acima existem florestas nativas desta arvore preciosa do Brasil meridional, como o são no norte a carnaubeira, a seringueira e a mangabeira, que fornecem a cera e borracha. ${ }^{19}$

Dentre as árvores, foi a erva-mate que apareceu, em primeiro plano, como elo das representações entre as demarcações de fronteiras e a base identirária do Paraná. Sebastião relaciona as questões de fronteiras com os produtos cultivados e enfatiza a erva-mate: "a árvore do matte constitue o principal ramo da industria extractiva paranaense. Milhares de arrobas de hervamatte são annualmente exportadas, principalmente para Buenos Aires, Montevidéo e Valparaiso". ${ }^{20}$

O mate tratava-se de um "nicho econômico alternativo, que lhes proporcionou uma atividade comercial intensa principalmente com o mercado platino [...]" (Corrêa, 2006, p.33 )21. Este produto teria sido o impulsionador da vida econômica no estado e tornava-se o principal em função, como se explicou, da terra favorável a seu cultivo. Diz o autor: "é, pois, o matte o ramo preponderante da nossa industria, aquelle que até hoje tem attrahido maior soma de braços e capitaes". ${ }^{22}$

Auguste de Saint-Hilaire ${ }^{23}$ já havia mencionado a erva-mate em seus estudos sobre as viagens que realizou no Brasil no século XIX. O naturalista

\footnotetext{
${ }^{18}$ PARANÁ, op cit., p. 106

${ }^{19}$ PARANÁ, op cit., p.110-111

${ }^{20}$ PARANÁ, op cit., p.107

${ }^{21}$ CORREAA, Amélia. S. Imprensa e política no Paraná: prosopografia dos redatores e pensamento republicano no final do século XIX. Dissertação de Mestrado. Programa de Pós-Graduação em Sociologia, da Universidade Federal do Paraná, Curitiba, 2006.

${ }^{22}$ PARANÁ, op cit., p.111.

${ }^{23}$ Naturalista francês que viajou pelo país no século XIX, 1822, já apontava em seus escritos que a natureza da região tinha sua síntese no Pinheiro do Paraná. Para ele, "o pinheiro era a planta que caracterizava a região, não apenas por seu aspecto e intensidade de incidência da paisagem, mas pela importância de
} 
a nomeou de Ilex paraguariensis e descreveu detalhadamente o seu uso no Paraná. De seus estudos ficou conhecido que é uma planta nativa da região Sul do continente americano, utilizada para preparar o chimarrão e o chá ${ }^{24}$. De suas informações importa ressaltar que por ser uma espécie nativa a erva-mate criou fronteiras simbólicas entre os estados e países do sul. Mas também representou, na cultura histórica local, o elemento central de desenvolvimento econômico regional até meados do século XX.

A ideia presente no manual de que o "meio" havia sido o principal elemento impulsionador da conquista paranaense do progresso visa demonstrar o mate como o núcleo irradiador de tal conquista. A geografia da região explicaria o clima favorável e o espírito empreendedor existente entre os grupos ervateiros, representantes das elites político-econômicas paranaenses do século XIX e do início do século XX. Isso porque, reafirma-se, a região possuía, na narrativa do autor, as melhores terras para o seu cultivo.

Após mencionar a importância do mate para o estado, o autor, ao referir-se a "indústria agrícola" do Paraná, afirma que a extração de pinho também constituía-se num elemento das riquezas naturais paranaenses junto com os outros produtos. $\mathrm{O}$ autor observa que, além do mate, o pinheiro representava a natureza do estado em sua generosidade na figura dos pinheirais. 0 pinheiro, possuindo um porte agigantado, se destacava no meio da floresta paranaense propiciando associá-lo a uma figuração simbólica - de grandeza - que se desejava para criar uma tradição que então se buscava. A analogia se realizava pensando na grandeza do "povo". Ou seja, "elevado à imagem e semelhança do pinheiro o povo paranaense desde sempre estivera representado naquelas terras pela figura dos pinheirais" ${ }^{25}$.

O pinheiro-do-paraná tornou-se símbolo da "população" paranaense na construção narrativa da identidade regional. Reconheceu-se que a árvore era uma espécie presente na paisagem há milhares de anos por isso um produto que pertencia aquele espaço. Além disso, a espécie teria originado do nome Curitiba, uma vez que na etimologia indígena significaria terras de pinheirais. A existência da árvore e a origem da palavra foram consideradas fortes motivos para representar discursivamente o pinheiro como símbolo regional.

\footnotetext{
sua madeira e do fruto, o pinhão, para os habitantes dos Campos Gerais”. (PEREIRA; IEGELSKI, 2002, p.52) ${ }^{24}$ PEREIRA, Marco A. M; IEGELSKI, Francine. O paraíso terrestre no Brasil: os Campos Gerais do Paraná no relato de Auguste de Saint-Hilaire. Revista de História Regional. N.7, Vol.1.Ponta Grossa, 2002, p.47-72.

${ }^{25}$ PEREIRA, Luís Fernando Lopes. Paranismo: o Paraná inventado: cultura e imaginário no Paraná da I República. Curitiba: Aos Quatro Ventos, 1997, p.143
} 
Além do mate e do pinheiro, outro produto compõe os símbolos da região. Sebastião informou que o café estava "[...] se desenvolvendo animadoramente no Paraná. Já existe notável plantação de café nos municípios do norte do Estado" ${ }^{26}$.

Presente desde o final do século XVIII no litoral dessa região, sendo consumido nos aldeamentos indígenas de São Pedro de Alcântara e de São Jerônimo ${ }^{27}$ e, ainda, na colônia militar de Jataí, o café tem sua produção intensificada em meados do século XIX pelas mãos de migrantes paulistas e mineiros. Ele adentrou no universo simbólico pela compreensão, entre os intelectuais que defendia a expansão do território, de que o café permitiu a ocupação e o desenvolvimento do interior do estado. Ele surge como símbolo na campanha de ocupação do sertão paranaense quando os poderes políticos se empenharam em colonizar o norte e sudoeste nos anos iniciais do século XX.

$\mathrm{Na}$ construção de um discurso que define a identidade regional, os elementos simbólicos se definiram entre os produtos comerciais que eram produzidos em terras paranaenses. A abordagem enfática na vida econômica para representar sua singularidade frente às diversas identidades regionais, que foram sendo construídas também nesse contexto no cenário brasileiro, tornou-se predominante na criação de dispositivos simbólicos sobre a região. Tal construção oferece para a história a unidade discursiva do espaço paranaense como continuidade histórica da nação. Sebastião Paraná afirmava: "Pode-se, pois, dizer que o Paraná assenta a sua riqueza em três grandes pedestaes: o matte, o pinheiro e o café" ${ }^{28}$. Essa tríade torna-se temática, memória social e referência para produzir conhecimentos sobre o Paraná, figurando-lhe um saber histórico e uma memória coletiva ${ }^{29}$.

Na busca por figurar um discurso de construção identitária, elegeram-se os elementos que se originam do cultivo da terra (erva-mate), do caráter do "povo" paranaense (pinheiro), da atividade manufatureira que atrairia o imigrante laboroso (café). Por isso, Sebastião, ao tratar das relações de trabalho, elaborou uma narrativa que exalta o imigrante:

Nesses pequenos centros de vida industrial, vê-se salutar a agitação agrícola que impressiona agradavelmente o espírito. Ahi se aprecia o esforço constante e sincero, o anhelo de progredir, a applicação ao trabalho quotidiano e a confiança

\footnotetext{
${ }^{26}$ PARANÁ, op. cit., p.107-108

${ }^{27}$ Ver: AMOROSO. Marta. Crânios e cachaça: coleções ameríndias e exposições no século XIX. Revista de História, n. 154, vol.1, 2006, p. 119-150

${ }^{28}$ PARANÁ, op. cit., p.107, grifo meu.

${ }^{29}$ HALBWACHS, Maurice. A memória coletiva. Trad. de Beatriz Sidou. São Paulo: Centauro, 2006.
} 
no meio onde extrangeiros e seus descendentes labutam confiantes nos dias do porvir. ${ }^{30}$

A propensão da índole do "homem paranaense" ao trabalho é uma construção que acontece, na escrita do autor, junto com o desenvolvimento da vida urbana na capital e a formação dos núcleos urbanos do interior. Sua visão republicana de progresso revestiu-se, pois, da defesa do trabalho livre. Identificar o trabalho livre com riqueza tornou-se uma luta política em decorrência do passado escravista.

Por meio da exaltação da produção do mate, do pinheiro e do café, criou-se a representação simbólica da região que enaltece as suas riquezas naturais, a grandeza do estado e o trabalho do "povo". Elementos ligados à sua formação econômica definem o projeto da elite local de negociar sua influência na construção da memória histórica do Paraná que ficou assentada na ideia do homem branco, laborioso e semeador do futuro.

\section{Considerações finais}

Este trabalho objetivou perceber a participação de intelectuais como professores-autores, na construção simbólica e discursiva da região que, no calor dos ideais republicanos, associa a representação de nação com suas partes constituintes - os estados. Nesse sentido, conferiu especial atenção ao manual escolar de Sebastião Paraná e no processo que emerge das relações sociais, como circulação de saberes e sociabilidade, com o intento de compreender como o professor-autor dialoga com um campo de saber escolar em construção que agrega sentido a uma "história e geografia regional" constituinte de um debate sobre território, natureza e região.

Ao problematizar os nexos relacionais existentes entre natureza, território e nação na construção narrativa de Sebastião Paraná, enfatizou-se o papel instituinte dos conhecimentos produzidos pelo professores-autores ${ }^{31}$ que atuou no ensino secundário e na Escola Normal da principal instituição de ensino da história da educação no Paraná nos anos iniciais do século XX. Conhecimentos que contribuíram para a produção de textos didáticos de

\footnotetext{
$\overline{{ }^{30} \text { PARANÁ, op cit., p.108 }}$

${ }^{31} \mathrm{O}$ conceito de professor-autor refere-se aos indivíduos que, nesse período, participavam da vida pública pela projeção intelectual e política. Sujeitos que publicavam seus escritos na imprensa, nos livros e artigos, além de exercerem o magistério em instituições de ensino secundário e superior.
} 
diferentes campos disciplinares que vão, no decorrer daquele século, definindo o papel do ensino da História e da Geografia nos cursos de formação de professores.

$\mathrm{Na}$ análise do manual observou-se que ao definir o estado do Paraná em suas demarcações territoriais e caracterizá-lo por meio de seus elementos naturais, intelectuais possibilitaram a criação de um sistema de signos como projeto social que se tornou conteúdo na afirmação das disciplinas de História e Geografia regionais como disciplinas escolares, inicialmente na formação de professores do ensino primário.

A legitimidade do território da região, suas fronteiras, ocupação do interior e preservação da representação de unidade foi possibilitada pela confirmação desse discurso no campo educacional. o espaço escolar torna possível a consolidação do projeto de identificação regional por intermédio do ensino da Geografia e da História desde o início da educação primária. De forma que os saberes geográficos e históricos sobre a região consolidaram, por meio da publicação de livros voltados à geografia e à história do estado, o discurso identitário baseada na tríade: mate, pinheiro, café.

Os conhecimentos geográficos e históricos produzidos pelos letrados da época forneceram ensinamentos para a definição do quadro regional e para a consecução de um projeto em que a região estaria integrada em seus aspectos naturais e memoriais. O manual de Sebastião Paraná, representativo dessa produção narrativa, definiu um saber sobre o tamanho dos rios, a altura das florestas, a riqueza dos produtos e as dificuldades a serem enfrentadas no avanço para o interior do estado, com a construção de estradas e ferrovias, a fim de promover um conhecimento escolar que possibilitava vê-lo como parte territorial da nação em desenvolvimento.

Neste texto apresentou-se a narrativa do autor que cria as imagens do Paraná como construídas da homogeneidade do território, da gloriosidade do "povo" e de seu labor. Tal representação tornou-se luta teórica para afirmar uma identidade que se define nas fronteiras de sua riqueza simbólica (mate, pinho, café) e cria uma memória histórica do estado. Nela, a identidade regional está relacionada à identidade nacional pelo território. Ou seja, pensou o "ser paranaense" dentro de um contexto maior que era pensar o "ser brasileiro". Os elementos simbólicos, por sua vez, não foram escolhas arbitrárias, estavam vinculados às práticas econômicas tradicionais cujas raízes se encontram no passado da comunidade economicamente dominante, legitimado pela intelectualidade na divulgação de uma história regional. 
A natureza e o território aparecem como objeto de intervenção do poder: sua qualificação, esquadrinhamento, história, entre outros, tornaram-se instrumentos poderosos para governar um "gigante pela própria natureza". Os conhecimentos geográficos e a história formaram, enfim, os saberes escolares produzidos no discurso do autor para a consolidação de uma brasilidade que pudesse se afirmar na República nascente.

A trama do livro desenrola-se em duas partes. A primeira envolve a descrição da geografia do Brasil e a segunda aborda os mesmos aspectos na descrição do Paraná. Ao descrevê-los Sebastião Paraná constrói como meios privilegiados de edificação de um saber escolar sobre a geografia e a história do Paraná que, como já se mencionou, expressaram a busca de uma identidade regional no espaço da nação. Saberes que marcaram a cultura histórica do Paraná durante muito tempo, sendo seus ecos sentidos na produção didática até hoje.

Artigo recebido para publicação em 07/07/2016

Artigo aprovado para publicação em 21/10/2016 